\title{
El Concepto Democrático \\ de la Literatura Española
}

Por J. A. DOERIG.

Al estudiar la civilización española - la iberoamericana se caracteriza por la misma estructura- nos llama la atención un rasgo característico por paradógico que nos parezca a primera vista. $\dot{c}$ Quién sospecharía en un pueblo que en la primera mitad de nuestra centuria ha aguantado dos regímenes autoritarios y cuya estructura económico-social lleva, en gran parte, las características en una nación estructurada en castas nobiliarias, una postura hondamente democrática en los poetas más representativos?

España pasa por el país absolutista por antonomasia: hay quien identifica a España con el absolutismo a secas. Hasta cierto punto y en el sentidó rnoderno político esta opinión es admisible para la época de los Austrias y de los Borbones. Y sin embargo, las instituciones democráticas tienen una historia muy venerable, teniendo presente que los numerosos Concilios de la era visigoda, es decir desde el año 409 hasta 711 pueden considerarse como precursores de los parlamentos modernos, puesto que los Concilios no sólo se ocuparon en asuntos eclesiásticos sino también en los de índole política. En efecto, la dependencia del rey de la Asamblea Conciliar se pone de manifiesto en el Fuero Juzgo promulgado por Eurico (466-84), una de las numerosas codificaciones de los visigodos, donde reza una frase: "Rey serás si fecieres derecho, et si non fecieres derecho no serás rey".

los reyes, que pueden ser depuestos por los Concilios. EI rey al ser elegido tiene que jurar en el Fuero, es decir en la Consti-

No puede expresarse más explícitamente la dependencia de tución según la terminología moderna. - El término "fuero"* dicho sea de paso, ha sido remozado en la Constitución más reciente de España que se.vuelve a llamar: Fuero de los Españoles (1945). En el fondo se ha anticipado en el Fuero Juzgo el 
principio de la monarquía constitucional.- No carecerá de interés señalar el hecho de que el Fuero Juzgo es el más antiguo documento del derecho germánico. Como se sabe se ha llevado a la práctica este principio más de 10,000 años más tarde en la Constitución inglesa de 1689 , producto de la así llamada Unbloody Revolution del año anterior.

Los Concilios eran en realidad los precursores de las Cortes, de las asambleas de los tres estados sociales. En este orden de ideas, resulta muy curioso lo temprano que aparece al lado del Clero y la Nobleza la burgesía de las ciudades y villas. A los ciudadanos de la pequeña villa de León en el Noroeste de España les pertenece la gloria de haber enviado la primera delegación a las Cortes del año 1138.

Los ingleses están muy orgullosos y con razón, de su Magna Carta, que sin embargo sólo se firmó 77 años más tarde y debe considerarse como una revuelta del Alto Clero y de la Nobleza, sin intervención de la burguesía ciudadana. Claro está, y nadie lo niega, que para la evolueión de la democracia moderna el ejemplo del Parlamento-Británío ha desempeñado un papel más trascendental que el modelo visigodo de España. A pesar de todo, estas condiciones-y estos hechos prueban a todas claras que en España existían y obraban fuerzas democráticas tal vez más tarde sólol subterf funearnente- que deben valorarse como resultado de una actitud hondamente democrática. Democrático era también el gesto generoso de Isabel la Católica al extender la ciudadanía castellano-leonesa a los indios. No menos democráticas las doctrinas de Francisco de Vitoria (1483 -1546) y Francisco Suárez y en último análisis también Las Casas que defendían la equiparación de los indios a los ciudadanos peninsulares. Grocio influído por ambos ejerció influencia en Juan J. Rousseau al concebir el contrato social que a su vez plasmó el pensamiento de los precursores de la independencia. Cabe por tanto ir en busca de las huellas de tal postura en las letras españolas, donde esta corriente se exterioriza menos en la superficie, más indirecta que directamente. Excluyo expresamente de mi estudio la literatura acusadamente política de los últimos tres siglos porque me interesa más señalar el concepto democrático como corriente básica en la literatura española en el Siglo de Oro.

Ya desde un principio de la época literaria propiamente dicha llama la atención lo íntimamente-popular del Poema del Cid frente a su réplica francesa, la Chanson de Roland. Aún ad- 
mitiendo que en su contenido y formalmente es dependiente de la epopeya francesa, el poema español habla mucho más el lenguaje del pueblo y es sobria expresión del sentir y pensar popular, mientras que en el modelo francés se acusan más bien rasgos auténticamente aristocráticos.

La característica popularesca asoma en general en la vieja poesía épica, mientras que la epopeya de la época posterior manifiesta su decadencia en el mismo apartamiento del pueblo. La novela caballeresca con el Amadís como producto representativo contrasta fundamentalmente en su actitud ética con su contrapartida francesa el Tristán que glorifica el adulterio al paso que el Amadís exalta la virtud popular de la fidelidad conyugal.

La literatura didáctica del siglo trece acusa rasgos democráticos en el sentido de que con ella entra a funcionar la crítica democrática y realística de la nobleza y hasta del clero. El siglo XIV, produce en Juan Ruíz Arcipreste de Hita (fallecido a mediados del siglo XIV), una figura literaria típicamente democrática. Su "Libro de Buen Amor" describe despiadadamente los abusos sociales de las clases aristocráticas y eclesiásticas y con preferencia se entrega a pintar como modelo la vida del hombre de la calle como diríamos hoy. Con toda su postura crítica frente a la vida, su concepto del mundo es absolutamente positivo, lo que no puede decirse de su contemporáneo más jóven López de Ayala (1332 - 1407) cuyo "Rimado del Palacio" satiriza las condiciones de su época. Su actitud ante la vida carece del humorismo del Arcipreste de Hita. Pero lo que tienen de común es su crítica democrática de las clases superiores de las que proceden ellos mismos. Es muy curioso que tengan sus correspondencias en la Inglaterra contemporánea: Geoffrey Chaucer (1340-1400) con sus "Canterbury Tales" es comparable a Juan Ruíz con su "Libro de Buen Amor" y López de Ayala recuerda a William Langland con su "Piers the Plowman" que es sencillo campesino que más tarde se identifica con Cristo.

La nota democrática del Conde Lucanor de Juan Manuel, quien es de sangre real, consiste en que el autor utiliza costumbres y anécdotas populares que entreteje en las encantadoras novelitas y cuentos, técnica comparable a la de Schatzkastlein del poeta suizo-alemán Johann Peter Hebel. Lo sorprendente en este caso es igualmente la ascendencia real del autor. 
En siglo XV, vuelve a ser un aristócrata, es decir, el Marqués de Santillana quien se inclina ante la sabiduría del pueblo coleccionando como uno de los primeros folkloristas europeos proverbios que publica bajo el título muy expresivo y gráfico: "Refranes que dicen las viejas tras el fuego". Este hecho prueba palmariamente que se toman en serio las clases humildes en sus expresiones intelectuales y que no separa un abismo infranqueable a las clases sociales. El gran poeta lírico del siglo XV, Jorge Manrique es otro noble que celebra en sus impresionantes "Coplas a la Muerte de su padre", a la Muerte como fuerza niveladora de las clases sociales.

Indudablemente el ejemplo más admirable de literatura democráticamente inspirada en el Romancero. Democrático en doble sentido tanto por la anonimidad de sus incontables autores como por la circunstancia de que todas las capas sociales, nobleza y pueblo, son objeto de este género de literatura. Representa la gran epopeya anónima a la cual el genio de! pueblo entero ha contribuído y en la que el individuo está relegado al segundo término. Es el respeto del hombre ante el hombre, la nota que informa todo este riquísimo tesoro de poesía popular. ¿Y quién lo duda hoy que este respeto es la conditio sine qua non para toda democracia auténtica, aun admitiendo las diferencias sociales exteriores? El renacimiento y el humanismo que cultiva en los demás países una literatura altiva, poco democrática, nace en España con la primera Gramática impresa de una lengua vulgar. ¿No es sintomático y simbolico que la edición de la Gramática de Antonio de Nebrija se realice en el mismo año, unos pocos meses antes, que el descubrimiento de América? La lengua del pueblo se hace objeto de una obra científica por un insigne latinista precisamente en la época en que fuera de España es desalojada por el brillo de las lenguas clásicas. El humanista Nebrija se da perfecta cuenta del alto significado que tendrá un idioma destinado para la expansión imperial:

"Cuando bien conmigo pienso, mui esclarecida Reina: i pongo delante de los ojos el antiguedad de todas las cosas: que para nuestra recordación e memoria quedaron escriptas: una cosa hallo e saco por conclusión mui cierta: que siempre la lengua fue compañera del Imperio: e de tal manera lo siguió: que juntamente comenzaron, crecieron e florecieron, e después, junta fué la caída de entranbos...

Lo que diximos de la lengua ebraica, griega e latina: podemos mui más claramente mostrar en la castellana: que tuvo su 
niñez en los tiempos de los hueces e Reies de Castilla e de León: e comenzó a mostrar sus fuerzas en tiempo del mui esclarecido e digno de toda la eternidad, el Rei Don Alonso el sabio...

La cual se estendió después hasta Aragón e Navarra e de allí a Italia siguiendo la compañía de los infantes que mandamos a imperar en aquellos Reinos. Y assí creció hasta la momonarchía e paz de que gozamos primeramente por la bondad e prouidencia diuina: después por la industria, trabajo e diligencia de vuestra real magestad. En la fortuna e buena dicha de la cual los miembros e pedazos de España que estauan por muchas parte derramados: se reduxeron e aiuntaron en un cuerpo e unidad de reino. La forma e travazón del cual assí está ordenada que muchos siglos viuiría e tiempos no la podrán romper ni desatar...

Porque si otro en nuestra lengua no se haze como en aquellas (se refiere a las gramáticas que ya tenían el latín y el griego), en vano vuestros cronistas e estoriadores escriven e encomiendan a inmortalidad la memoria de vuestros loables hechos: e nosotros tentamos de passar en castellano las cosas peregrinas e extrañas: pues que aqueste no puede ser sino negocio de pocos años. I será necesaria una de dos cosas: o que la memoria de vuestras hazañas perezca con la lengua: o que ande peregrinando por las naciones extrangeras: pues que no tiene propia casa en que puedaliporate Letras

El tercero provecho deste mi trabajo puede ser aquel que cuando en Salamanca di la muestra de aquesta obra a vuestra real magestad: e me preguntó que para que podría aprovechar: el mui reverendo padre obispo de Avila me arrebató la respuesta: e respondiendo por mí dixo: Que después de vuestra alteza metiese debaxo de su jugo pueblos barbaros e naciones de peregrinas lenguas: e con el vencimiento aquellos tenían necessidad de recibir las leyes: que el vencedor pone al vencido e con ellas nuestra lengua: entonces por esta mi arte podrían venir en el conocimiento de ella como agora nosotros deprendemos el arte de la gramática latina para deprender el latín".

La lengua del pueblo es, por así decirlo, declarada mayor de edad y elevada al mismo rango que las lenguas de Roma y Atenas. Sin exageración se puede hablar del inicio de una nueva era desde el punto de vista lingüístico.

Hasta en la poesía lírica renacentista con sus productos de tendencia italianizante, cultivada sobre todo por una aristocra- 
cia intelectual con Garcilaso de la Vega, no callan las voces populares.

Muy sorprendente resulta para nuestro estudio el comprobar que la literatura mística, por definición esotérica, en España lleva rasgos acusadamente populares en su representante más preclaro. Con todo lo personal de su estilo, escribe Santa Teresa de Avila, hija de padres burgueses, en la lengua del pueblo, demostrando con esto que sus visiones extáticas no la han hecho perder el contacto con el pueblo. La famosa frase tantas veces citada "Entre los pucheros anda el Señor" simboliza su hondo arraigo en el alma popular. Su estilo es tan llano, tan sencillo que hasta los pobres de espíritu podrían seguir sus descripciones místicas. Contrastándola con la mística alemana, la española está profundamente arraigada en la manera de pensar y sentir del pueblo.

En el campo de la literatưra dramática, se observan desde sus comienzos rasgos típicamente democráticos. Palpablemente se asoma el parentesco con la poesía popular en la obra del dramaturgo bilinguie Gil Vicente que adopta una posición crítica frente a las condiciones sociales y el clero. Esta crítica expresa la manera de ver las cosas de la gente del pueblo. De sus famosas barcas - de las que "La Barca de la Gloria" está en castellano- dice Menéndéztyc Pélayoraque son una especie de transformación de las antígurásirt'Danzzas"de la muerte" no en lo que tenían de lúgubre y aterrador, sino en lo que tenían de sátira general de los vicios, estados, clases y condiciones de la sociedad humana. Su popularismo llega hasta el lenguaje que no vacila en ser encantadoramente incorrecto a modo del pueblo. Tampuco respeta el género sagrado de los autos que francamente seculariza en ciertas piezas (Auto de los cuatro tiempos). Incluso en sus comedias de argumento clásico entremezcla mucho material folklórico autóctono: supersticiones, refranes, conjuros, canciones de cuna y de mozas del campo. (Comedia de la Rubena).

Lope de Rueda que era al igual que Shakespeare actor y autor, populariza la comedia como entretenimiento espectacular para todas las capas sociales que será conformada en este sentido por Lope de Vega. Juan de la Cueva (1560 - 1610) documenta en postura democrática en materia cultural defendiendo en su tratado teórico "Ejemplar Poético" contra el drama humanista culto la comedia por corresponder más al sentir nacional. La época y el carácter teórico de un tratado ponen de 
manifiesto que se considera en plena conciencia y por motivos intrínsecos el teatro de interés para el pueblo entero y no para una aristocracia intelectual.

Caracteriza la situación dramatúrgica de la España renacentista el hecho sintomático de que precisamente la primera y más importante comedia de esta época "La Celestina" tiene por protagonista, no una diosa de la antigüedad, sino la figura muy popular, para no decir vulgar, de una embaucadora. Los caracteres de "La Celestina" que proceden de los bajos fondos de la sociedad por repugnantes que sean moralmente, no carecen de rasgos simpáticos.

La esplendorosa falange de dramaturgos del Siglo de Oro con los Lope de Vega, de Ruíz de Alarcón, Tirso de Molina, Rojas Zorrilla, Calderón, Moreto, para no citar más que las figuras más destacadas, tienen esto de común: están todos al servicio del teatro popular en el sentido más lato y comprensivo de la palabra. Creada para entretener a un público insaciable sin distinción de clases y en francal consonancia con el gusto popular, la comedia española se elevara una altura que nunca había de alcanzar en tiempos posteriores. Al igual que el drama shakespeariano, la comedia, conforme al gusto del pueblo, se burla de las tres unidades del drama clásico-humanista, mezclando lo trágico con lo cómico, insertando romances y letrillas populares para satisfacer los capichios detas multitudes que acuden a la comedia de cuyo público nos ha dejado Juan de Zabaleta un cuadro vivísimo y muy pintoresco en su "Día de Fiesta por la tarde" (Madrid 1659). En este público abigarrado hay de todo: méndigos y matronas, duques y damas ligeras, condes y cuchilleros, padres venerables y pilluelos impertinentes, artesanos y artistas, obispos y obreros, pobres hidalgos y ricos grandes de España: no hay capa social, ni profesión que no esté representada en este público ávido y agradecido que adora a sus favoritos entre los autores y actores pero que está igualmente dispuesto a quitarle su veleidoso favor si no halaga sus caprichos $\mathrm{Y}$ el poeta más genial de la época no ha vacilado en inclinarse ante las veleidades del hombre - masa en el sentido orteguiano. $\mathrm{Y}$ actúa en plena conciencia de lo que hace como confiesa francamente en su Arte de hacer comedias. A lo abigarrado del público corresponde la enorme variedad de figuras que aparecen en la escena todavía inconcebiblemente sencilla en la época de Lope. En tanto que en la vida dramatúrgica de lengua a!emana aún en la primera mitad del siglo XVIII se pierde el 
tiempo discutiendo si representantes de la burguesía pueden fi. gurar en las tragedias o sólo en comedias bufas, exponiéndola a la risa general. (Recuérdese: Versuch einer kritischen Dichtkunst vor die Deutschen de Gottsched del año 1730), encontramos la comedia española ya esencialmente democratizada 150 años antes. Entre hombres no se admiten diferencias, no se respetan posiciones sociales, idea y actitud que ya asoma en las cartas a Lucilio del hispano-romano Séneca (65 años después de $\mathrm{Cr}$.), cuya influencia se acusa palpablemente en escritores y tratadistas tan notables como Fox Morcillo, el Padre Nieremberg, Saavedra Fajardo, P. Ribadeneyra, Mateo Alemán, autor del Guzmán de Alfaranche, Melchor Cano, Fray Luis de Grana. da, Baltazar Gracián (Oráculo manual) hasta el mismo Cervantes y San Ignacio de Loyola. La traducción castellana de la Epistola de Séneca fue reeditada cuatro veces en el siglo XVI (1502 y 1510 en Toledo; 1529 en Alcalá y 1551 en Amberes), de manera que no podían dejar de tener resonancia directa en los autores dramáticos, si es que consideramos necesaria una influencia externa; aunque yo perşonalmente estoy más inclinado a suponer un substracto racial desarrollado y corroborado por la filosofía cristiana que en sus representantes españoles no se cansa de acentuar el aspecto ético y la diginidad del hombre, considero una influencia de las doctrinas de Francisco de Victoria y Fr. Suárez sobre los autores literarios, no sólo posible sino sumamente probable dáda la resonancia que tuvieron en su época.

Así vemos campear en las comedias del Siglo de Oro un espíritu democrático que en vano buscaríamos en el resto de Europa, tal vez descontando a Shakespeare. En Estrella de Sevilla, Lope, por monárquico que fuera, nos presenta en Sancho IV, un monarca malvado que abusa de su alta posición para satisfacer sus apetitos culpables. Más sabor democrático hallamos aún en Peribañez del mismo autor; en estas comedias, el labrador mata a un alto funcionario real, que intenta afrentar la honra de su esposa. El rey agraviado perdona a Peribáñez al saber que ha obrado en defensa de su honra, reconociendo el derecho a su honra personal a sus súbditos más humildes. En este conjunto, la obra más interesante me parece Fuente Ovejuna, en que toda una aldea es el protagonista, anticipándose hasta cierto punto al Tell de Schiller. Lope hace hablar al alma del pueblo atropellado por los desmanes de un comendador. Muerto éste a manos de un hombre de la aldea amotinada, los Reyes Católicos mandan un juez para hacer el proceso al cul- 
pable. Sin embargo, resulta imposible sacar del pueblo el nombre del culpable. Con impresionante entereza, todos los procesados, es decir, el pueblo entero contestan a la pregunta del Juez:

- ¿Quién mató al comendador?

-Fuente Ovejuna, Señor.

$-¿$ Y quién es Fuente Ovejuna?

- Todos a una.

Lope, en esta comedia, ha dado prueba de una excepcional psicología de las muchedumbres, mucho antes de Schiller y mucho antes de ser acuñado el término. Recuerda en cierta sentido la célebre pieza moderna del norteamericano Steinbeck: The Moon is down. Se podría llamarla el drama de la resistencia española dentro de un cuadro distinto, el drama de la autoafirmación de la comunidad agraviada.

La misma temática, con más perfil individual se halla en el Alcalde de Zalamea de Calderón, que que hizo más que refundir una comedia lopesca: El mejor alcalde el Rey. El mérito de Calderón está en la-mejor concentración dramatúrgica, evitando desdoblamientos-innecesarios y disgresiones líricas. Rojas Zorrilla que está incFuído en el cielo calderoniano vuelve al mismo tema en la comedia: "Del rey abajo, ninguno", también conocida con el título acusadamente democrático: "El labrador más honrado", que trata de un noble que atropella la honra de un campesino. Como sospecha primero en el ofensor a la persona del rey, se ve reducido a la inactividad. Sólo al darse cuenta de su error, procede a la venganza pero completa y definitiva. También esta vez, el rey sanciona la justicia que se ha administrado el ultrajado mismo. Este título de Rojas: "Del Rey abajo, ninguno" nos da la clave para el concepto de democracia que corre como un hilo rojo por toda la literatura dramática del Siglo de Oro. La institución de la monarquía y la persona del rey no están en tela de juicio: los dos son absolutamente tabú. Sin embargo, con una limitación fundamental que Calderón ha formulado insuperablemente en el "Alcalde de Zalamea": Al preguntar Don Lope a Crespo si sabe lo que debe al Rey, éste le contesta con dignidad orgullosa:

Con mi hacienda, sí, con mi fama no.

Al rey la hacienda y la vida

se ha de dar, pero el honor

es patrimonio del alma,

y el alma sólo es de Dios. 
Con toda franqueza, yo no conozco fórmula más concisa, más definitiva de la dignidad humana en toda la literatura universal; esta definición arraiga el concepto democrático en una base metafísica. Además, hay que tener en cuenta que esta limitación del poder real fue formulada por un poeta que entregó toda su vida al servicio del rey. La influencia de la fílosofía suareciana me parece palmaria en esta actitud independiente.

Es más, el título de la comedia de Rojas Zorrilla refleja otro concepto democrático. Por debajo de la persona del rey, no valen las diferencias sociales entre las distintas clases, y los crímenes perpetrados por los representantes de la más alta aristocracia fueron perseguidos con el mismo rigor que los de la gente más humilde, por lo menos poéticamente. Un aspecto muy curioso e instructivo puede verse en que los reyes invariablemente sancionan los actos más violentos del pueblo que se rebela contra los funcionarios reales que abusan de su posición oficial. Si tenemos presente que a estas comedias con frecuencia asistían los mismos monarcas, es lícito suponer que los autores contaban con el consenso real. También se puede interpretarlo como lección dada a los propios monarcas y sus funcionarios. Lección hondamente democrática, en particular, si tenemos en cuenta la época, que en otros países se distingue por su desprecio de las clases campesinas.

El gran Calderón en su comedia "La Vida es Sueño" que conduce temáticamente a los autos sacramentales da prueba patética de un hondo democratismo metafísicamente fundado al quejarse Segismundo de su condición humana que no exceptúa al mismo monarca.

$$
\begin{aligned}
& \text { Sueña el rey que es rey, y vive } \\
& \text { con este engaño mandando, } \\
& \text { disponiendo y gobernando. } \\
& \text { Y este aplauso que recibe } \\
& \text { prestado, en el viento, escribe } \\
& \text { en cenizas la convierte } \\
& \text { la muerte. }
\end{aligned}
$$
sociales:

Continúa más adelante después de enumerar varias clases Sueña el rico en su riqueza...

Todos sueñan lo que son.

Para este cortesano acabado, las diferencias sociales se reducen a una ficción, idea que recurre con una obsesión insistente en comedias y autos. Sobre todo en el "Gran Teatro del Mundo" subrayó lo ficticio de las categorías sociales que se re- 
velan como simples papeles asignados a los hombres cuyo único mérito consiste en él cómo desempeñar este papel.

En cierto sentido patentiza también la actitud democrática de la comedia española en la circunstancia de que los poetas llevaron los temás más complejos de la teología a la escena como por ejemplo el célebre pleito teológico entre el Jesuita Molina y el domínico Báñez sobre el libre albedrío y la predestinación planteado en el "Condenado por desconfiado" atribuído a Tirso de Molina.

El considerar al pueblo maduro y capaz para juzgar tan complicado problema supone un criterio muy democrático desde el punto de vista teológico. Lo mismo puede decirse del género genuinamente español: el auto sacramental que trata de los problemas dogmáticos más complejos. El español es, por así decirlo, demócrata en la esfera religiosa y tiene mucha confianza con Dios y los Santos.

El gran satírico de la incipiente decadencia Francisco Quevedo (1580 - 1645) se revela como demócrata de pura cepa al estilo del Arcipreste de Hita. En sus "Sueños" pasa revista a todas las clases sociales de su épocá a la manera de la Divina Comedia. Es cuento de los "Sueños": "El alguacil alguacilado" describe por boca de un diablo cómo está lleno el infierno de poetas, mercaderes, funcionarios, ministros, aduladores, clérigos, etc. Toda la gamailsbeitadadparecesen una atroz burla. "La hora de todos", otro curentó cide "Fosvet'Sueños" pinta la conmoción que sufre el mundo al hacerse un equitativo reparto de las cosas y es una fantástica sátira política y social de saber auténticamente democrático.

De tal cabe calificarse todo el género de la novela picaresca que representa una visión del mundo a través de la perspectiva democrática del hombre de la calle. La resonancia que tuvo la novela picaresca en aquel entonces puede inferirse de la enorme difusión dentro y hasta fuera de España, donde fue imitado sobre todo en Inglaterra (Fielding: The Adventures of Joseph Andrews, The Life of Jonathan Wild the Great Tom Jones y Smollett: Roderick Random), en Francia (Lesage: Gil Blas de Santillane y Le Diable boiteux), en Alemania (Grimmelshausen: Simplizissimus). Hasta la epopeya nacional si se nos permite este término, el Quijote lleva caracteres indiscutiblemente picarescos. Sin embargo, no se agota en este aspecto su substancia entrañablemente popular en el sentido democrático. Su protagonista es pobre a quien vincula una profunda y sincera amistad con su escudero, encarnación del pueblo por definición. 
A pesar de su materialismo y de su ambición un tanto ridícula de pequeño burgués, no carece de rasgos genuinamente simpáticos. En el Quijote poseemos la imagen del pueblo español en su totalidad. En este aspecto total y comprensivo puede verse una expresión esencial del concepto democrático de la literatura española por tratarse no de una obra cualquiera, sino de una obra maestra de la más alta categoría.

Por paradójico que parezca, el propio concepto del hidalgo español reviste ciertos caracteres democráticos. Ya el hecho de que en el Siglo de Oro hubiera una verdadera manía entre la gente de todas las clases burguesas de adornarse de blasones, armas y ejecutorias, prueba que el pueblo como tal se sentía de estirpe hidalga. En efecto, la promoción a la nobleza era posible para todos los que se distinguían en las numerosas guerras. A diferencia del gentleman coetáneo, la riqueza personal no era condición previa para pertenecer a la clase hidalga. Pobreza e hidalguía no se excluían por escencia como era el caso en Inglaterra, hasta muy entrado al siglo XIX. La descendencia de por sí no ennoblece todavía, si nonobliga a ser noble. La verdadera nobleza está únicamente en lávirtud. Donde hay virtud, cabe por eso también la nobleza. Todas las demás condiciones son accesorias. La virtud se manifiesta en los actos conforme se reconoce el árbol por los frutos. Cada uno es hijo de sus obras. Y finalmente un concepto de famas elevada categoría ética: Las obras se valoran por el esfuerzo y no por el éxito.

La Crónica Victorial a la pregunta: ¿qué es noble y nobleza? Responde en términos muy llanos y lisos: un corazón de virtudes. El mismo Cervantes, repetidas veces, deja entrever que la posición social no se identifica con nobleza al definir: "La verdadera nobleza está en la virtud", o "El pobre si puede tener honra, no empero el malvado", o consolando al pobre caballero: "El pobre hidalgo sólo dispone de una manera para mostrar que es hidalgo: a saber la de la virtud."

Claro que la literatura barroca ha dado de sí también frutos extraños como el conceptismo y el culteranismo, que significa lo diametralmente opuesto a lo popular dirigiéndose a una minoría que se creía muy selecta. Pero el mismo Góngora en sus años mozos compuso romances al alcance de todos. Hasta apoyan y confirman la tesis de la postura fundamentalmente democrática, las aberraciones de Góngora y sus secuaces en su apartamiento del pueblo, que hay que valorar en su justo valor: como fenómenos de degeneración. 
Sin pecar de exagerado, parece casi una verdad perogrullesca el afirmar que la literatura alcanza su apogeo a medida que procede del pueblo en su totalidad y que es la expresión genuina de su manera de ser y sentir. Los representantes clásicos, Cervantes, Lope y hasta Calderón, a mi modo de ver, prueban la tesis del concepto democrático de las letras españolas de un modo palmario, así que podemos prescindir de la época postbarroca. Ortega y Gasset parece confirmar nuestro concepto de la corriente democrática en la literatura española de una manera más amplia todavía al decir que todo lo que se ha hecho en España, ha sido hecho por el pueblo.

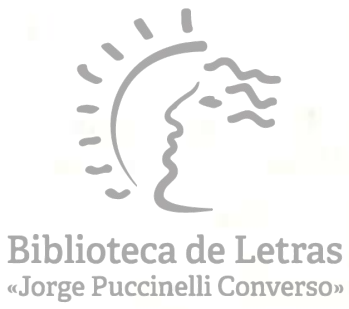

